\title{
More or less: Sometimes more is more if it's the lesser of evils
}

\author{
Jonathan M. Chen, MD
}

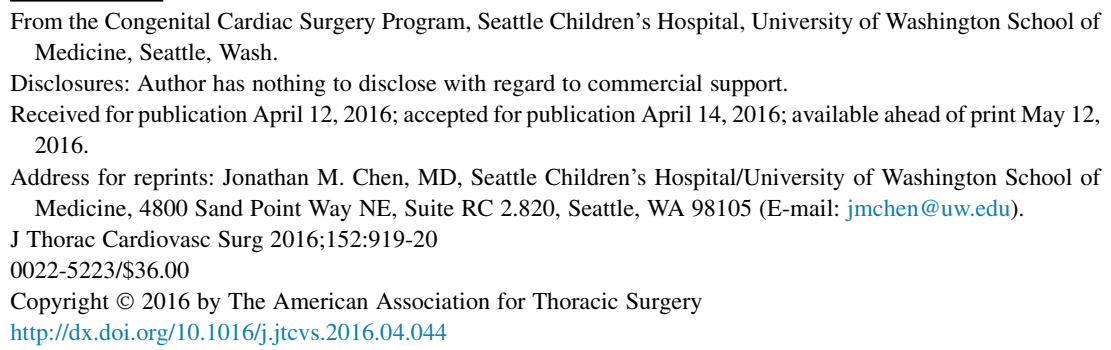

From the Congenital Cardiac Surgery Program, Seattle Children's Hospital, University of Washington School of Medicine, Seattle, Wash.

Disclosures: Author has nothing to disclose with regard to commercial support.

Received for publication April 12, 2016; accepted for publication April 14, 2016; available ahead of print May 12 , 2016.

Address for reprints: Jonathan M. Chen, MD, Seattle Children's Hospital/University of Washington School of Medicine, 4800 Sand Point Way NE, Suite RC 2.820, Seattle, WA 98105 (E-mail: jmchen@uw.edu).

J Thorac Cardiovasc Surg 2016;152:919-20

$0022-5223 / \$ 36.00$

Copyright (c) 2016 by The American Association for Thoracic Surgery

http://dx.doi.org/10.1016/j.jtcvs.2016.04.044

For infants whose physiology relies on a surgical systemicto-pulmonary artery shunt, the balancing of circulations so as to provide ideal amounts of both systemic output and pulmonary blood flow often remains a Goldilocks paradox, where a radical change in either can have catastrophic consequences. Because of this, the constant risk for major shunt complications remains concerning, causing us to admonish the house staff that the procedure never be referred to as "just a shunt." Concurrent advances in the development of rapid-response extracorporeal membrane oxygenation (ECMO) programs have allowed for greater salvage of patients who succumb to cardiac arrest, but for those with patent systemic-pulmonary shunts, the conundrum remains as to how to reproduce a balanced circulation effectively while on device support. Simply put, one can either limit the pulmonary blood flow (ie, clip the shunt) to encourage cardiac (ie, ECMO) output, or increase ECMO output with a patent shunt at the risk of pulmonary overcirculation. In this issue of the Journal, the Emory group presents compelling data that we rethink whether "more is more," and in fact that (as has been previously suggested) simply increasing ECMO flow without restricting shunt caliber may obtain good results in dire situations. 1,2

The entire cohort in this study demonstrated a survival to ECMO decannulation of $71.1 \%$, and survival to hospital discharge of $50.9 \%$, findings largely unchanged for those infants and neonates, those shunted or unshunted, and those with Norwood stage I palliation. To the uninitiated, these may seem concerning outcomes, but they are in fact comparable-if not superior-to most. ${ }^{3}$ Those with a systemicpulmonary shunt demonstrated higher pre-ECMO and peak serum lactate levels, and longer times to achieve lactate clearance and negative fluid balance-a small price to pay for comparable overall survival. The nonshunted patients in the study also required considerably longer ECMO support times, a fact that may contribute to the "equalization" of overall survival—namely that, although requiring higher flows, an infant with an isolated shunt problem

\section{References}

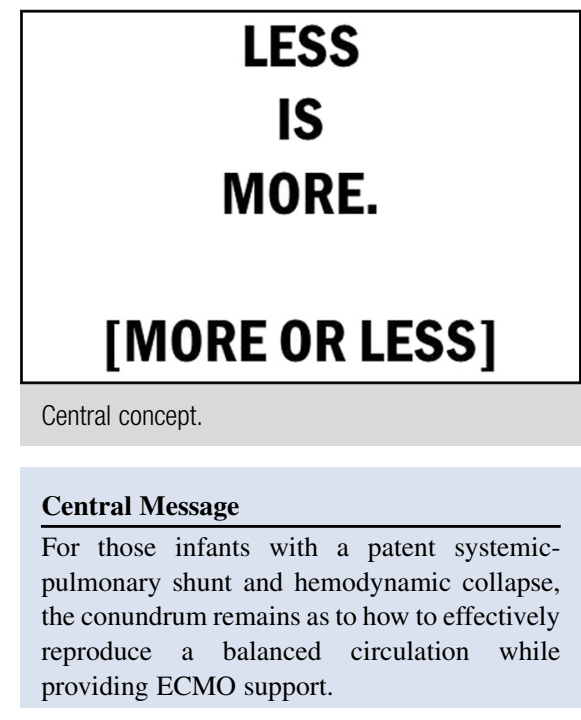

See Article page 912.

(and salvageable cardiac function) ultimately may be weanable sooner than a patient with 2-ventricle physiology awaiting myocardial recovery. These data are consistent with previous studies demonstrating superior ECMO survival in patients with isolated shunt thrombosis. ${ }^{4}$

Moreover, dogma would suggest that carotid cannulation in the setting of a modified Blalock-Taussig shunt could presage proximal shunt occlusion and instigate thrombosis. One-fifth of those shunted underwent neck cannulation, all of whose shunts remained patent through the ECMO course with or without intervention.

While a retrospective single-center study cannot promote or refute the approach of shunt restriction to balance shunted physiology on ECMO, these data argue in favor of simplicity. Like other series from large ECMO centers, these data do beg for a disclosure of 'best practices' to achieve such results - when to start hemofiltration? How aggressive to be about shunt revision? When to initiate support? Does this management strategy apply to those with ductal stents? The first step in this process is debunking mythology, as “people saying 'it can't be done' are always being interrupted by somebody doing it." 5

1. Botha P, Deshpande SR, Wolf M, Heard M, Alsoufi B, Kogan B, et al. Extracorporeal membrane oxygenator support in infants with systemic-pulmonary shunts. J Thorac Cardiovasc Surg. 2016;152:912-8.

2. Jaggers JJ, Forbess JM, Shah AS, Meliones JN, Kirshbom PM, Miller CE, et al Extracorporeal membrane oxygenation for infant postcardiotomy support: significance of shunt management. Ann Thorac Surg. 2000;69:1476-83. 
3. McMullan DM. Is there a concerning trend in extracorporeal life support utilization for single-ventricle patients? Pediatr Crit Care Med. 2016;17:259-60.

4. Allan CK, Thiagarajan RR, del Nido PJ, Roth SJ, Almodovar MC, Laussen PC. Indication for initiation of mechanical circulatory support impacts survival of infants with shunted single-ventricle circulation supported with extracorporeal membrane oxygenation. J Thorac Cardiovasc Surg. 2007;133: 660-7.

5. Post LF (ed). The Public. no. 257, March 7, 1903:766. 